milieux, for example assessing patient care on a multidisciplinary basis, will also regard these commitments as 'fixed'. It seems unlikely therefore that psychiatrists will have difficulty in reaching agreement with managers on this issue.

(c) "requirements to participate in medical audit (in the light of relevant Department guidance)". As yet, no such guidance has been issued (July 1990), but nevertheless psychiatrists will welcome recognition of audit activity as a contractual commitment. The College (1989) has already published preliminary guidelines on audit and is now engaged in drawing up a more extensive and definitive statement. How much time for audit the Government will fund is unclear; one weekly session, as suggested by some Royal Colleges, will certainly mean a reduction in clinical duties leading to demand for many additional posts. In psychiatry this issue is not simply one of funding but of manpower, since we know that one Region alone has over 50 unfillable consultant posts in psychiatry due to lack of suitably trained applicants. It will be necessary, therefore, for psychiatrists to negotiate audit time with a sensitive awareness of local conditions.

(d) "details of out of hours responsibilities, including rota commitments". Divisions of Psychiatry should be able to work out local rota and on-call commitments, assessing these in terms of notional half days. However, in psychiatry 'call-out' frequency is low compared to other specialties (e.g. neo-natal paediatrics) and this will need to be reflected in each individual contract. Hopefully the CCSC specialty sub-committees will give guidance in this area. However, consultant psychiatrists should take great care that they do not lightly agree to par- ticipate in a 24-hour on-call rota for the purposes of Section 12(2) of the Mental Health Act. There is currently much pressure from the Mental Health Act Commission and from the Department of Health for Regions to set up such rotas. While the College recognises that it is good practice for consultants to take part, it is clear that Terms and Conditions of Service for Consultants does not include this duty.

(e) "budgeting and other management responsibilities, where appropriate". It will be necessary for all psychiatrists to be involved, albeit in varying degrees, in the many organisational changes envisaged in the White Paper and their new contracts should reflect this. Those who take on such key roles as Clinical Director, resource management leadership or audit co-ordinator will need to devote substantial time to these activities and it is unlikely that one to two sessions will allow for this.

Are we to conclude that Government, which has repeatedly voiced its desire to involve clinicians in management, is in fact signalling quite the opposite intention?

\section{References}

CCSC (1990) Guidance to Consultants on Consultant Contracts. CCSC, Secretariat, BMA House, Tavistock Square, London WCIH 9JP.

DePARTMENT OF HEALTH (1989) Working for Patients (CM 555). London: HMSO.

NHS Consultants: Appointments, Contracts and Distinction Awards Working for Patients - Working Paper 7.

HAvard, J. (1990) A revised consultant contract. British Medical Journal, 300, 1221.

Royal College of Psychiatrists (1989) Preliminary report on medical audit. Psychiatric Bulletin, 13,577-588.

\title{
College guidance on consultant contracts and job plans
}

There are certain general principles in psychiatry concerning consultant activities which need to be borne in mind. Consultant psychiatrists are likely to be rather more "mobile" than many other consultants and to do their work in clinics, domestic settings, or general practice settings outside their hospitals Many consultants have regular administrative liaison work, not only with other carers, but with other organisations such as Social Services, Housing Departments etc., as part of planning and maintaining liaison with these agencies. It is not at all uncommon for child psychiatrists or psychogeriatricians to make regular visits to children's homes or to old people's homes, to give support and training to their staff.

Most consultants will be doing at least one ward round a week, one out-patient and one follow-up clinic a week. Regular teaching occasions and audit meetings and management meetings, all involving other staff, should also be included under fixed com- mitments, It is a College recommendation, supported by Postgraduate Deans, that at least one session of consultant time is required for teaching both trainees and continuing medical education, and another for audit. In psychiatry, purely medical audit has perhaps less power than clinical audit, involving the work of other staff in the multidisciplinary team. For instance, "untoward events" such as suicide in hospital or serious suicidal attempts, or serious violence, are nearly always related to the functioning of a clinical team rather than the functioning of one particular individual.

Time in NHS duties, other than fixed commitments, include many of the activities mentioned outside hospital. It should also include work for the College, which is helping training or audit or improving the work of the NHS.

Approved by Executive and Finance Committee, September 1990. 